out strategies for pain management could improve this PCS values and therefore reduce the need for TKR. Furthermore, this study also highlights the two mainly types of OA etiology: mechanical and inflammatory. It suggests that inflammation is mostly responsible for OA progression in patients with low BMI, and plays a strong role in women pathology. Finally, specific treatments targeting central pain sensitization could also improve the management of the pathology in women.

References:

[1] Guccione AA, Felson DT, Anderson JJ, Anthony JM, Zhang Y, Wilson PW, et al. The effects of specific medical conditions on the functional limitations of elders in the Framingham Study. Am J Public Health. 1994 Mar;84(3):351-8.

[2] O'Neill TW, Felson DT. Mechanisms of Osteoarthritis (OA) Pain. Curr Osteoporos Rep. 2018 Oct;16(5):611-6.

[3] Dieppe PA. Relationship between symptoms and structural change in osteoarthritis. what are the important targets for osteoarthritis therapy? J Rheumatol Suppl. 2004 Apr;70:50-3.

Acknowledgments: MICINN Funds are acknowledged (HOLOA-DPI201680283-C2-1/2-R)

Disclosure of Interests: None declared

DOI: 10.1136/annrheumdis-2020-eular.5586

\section{FRI0427 EULAR RECOMMENDATIONS FOR INTRA-ARTICULAR TREATMENTS FOR ARTHROPATHIES}

J. Uson Jaeger ${ }^{1}$, E. Naredo ${ }^{2}$, S. C. Rodriguez-García ${ }^{3}$, R. Castellanos-Moreira ${ }^{4}$, T. O'neill ${ }^{5}$, H. Pandit ${ }^{6}$, M. Doherty ${ }^{7}$, M. Boesen ${ }^{8}$, I. Möller ${ }^{9}$, V. Vardanyan ${ }^{10}$, J. De la Torre-Aboki ${ }^{11}$, L. Terslev ${ }^{12}$, F. Berenbaum ${ }^{13}$, M. A. D'agostino ${ }^{14}$, W. U. Kampen ${ }^{15}$, E. Nikiphorou ${ }^{16}$, I. Pitsillidou ${ }^{17}$, L. Carmona ${ }^{18} .{ }^{1}$ Hospital Universitario de Móstoles, Móstoles, Spain; ${ }^{2}$ Hospital Universitario Fundación Jiménez Díaz, Madrid, Spain; ${ }^{3}$ Hospital de La Princesa, Madrid, Spain; ${ }^{4}$ Hospital Clínic de Barcelona, Barcelona, Spain; ${ }^{5}$ Manchester University, Manchester, United Kingdom; ${ }^{6}$ University of Leeds, Leeds, United Kingdom; ${ }^{7}$ University of Nottingham, Nottingham, United Kingdom; ${ }^{8}$ Bispebjerg and Frederiksberg Hospital, Copenhagen, Denmark; ${ }^{9}$ Institut Poal de Reumatologia, Barcelona, Spain; ${ }^{10}$ Mikayelyan University Hospital, Yerevan, Armenia; ${ }^{11}$ Hospital General Universitari d'Alacant, Alacant, Spain; ${ }^{12}$ Rigshospitalet, København, Denmark; ${ }^{13}$ AP-HP Sorbonne Université, Inserm, Paris, France; ${ }^{14}$ APHPUniversité Paris-Saclay Versailles, Boulogne-Billancourt, France; ${ }^{15}$ Rad. Allianz, Nuklearmedizin Spitalerhof, Hamburg, Germany; ${ }^{16}$ King's College London, London, United Kingdom; ${ }^{17}$ Cyprus League Against Rheumatism, Nicosia, Cyprus; ${ }^{18}$ InMusc, Madrid, Spain

Background: Intra-articular therapies (IAT) are widely used in clinical practice to treat patients with rheumatic and musculoskeletal diseases (RMDs). Many factors influence their efficacy and safety. There is a wide variation in the way IATs are delivered by health professionals. In an attempt to standardise these procedures, evidence-based recommendations are the right way forward.

Objectives: To establish evidence-based recommendations to guide health professionals using IAT in adult patients with peripheral arthropathies.

Methods: At a first face-to-face meeting, the results of an overview of systematic reviews were presented to the multidisciplinary task force of members from 8 countries. The aim, scope and outline of the taskforce were also established at this meeting. Thirty-two clinical questions ranked for priority (relevance for practice plus feasibility) drove the systematic reviews performed by two fellows. In addition, two surveys addressed to physicians, health professionals and patients throughout Europe were agreed to acquire more background information. At the second face-to-face meeting, the evidence for each research question was discussed, and each recommendation shaped and voted in a first Delphi round. Level of agreement was numerically scored 0 to 10 (0 completely disagree, 10 completely agree). All panellists voted anonymously using a sli. do app. Agreement needed to be greater than $80 \%$ to be included in a second Delphi round, which also allowed reformulation of statements. Finally, a third Delphi round was sent to the taskforce. The level of evidence was assigned to each recommendation according to the EULAR SOP for establishing recommendations.

Results: Recommendations focus on practical aspects for daily practice to guide health professionals before, during and after IAT in adult patients with peripheral arthropathies. Five overarching principles were established, together with 11 recommendations that address the following issues: (1) patient information; (2) procedure and setting; (3) accuracy issues; (3) routine and special antiseptic care; (4) safety issues and precautions to be addressed in special populations; (5) efficacy and safety of repeated joint injections; (6) the usage of local anaesthetics; and (7) aftercare. The document includes the supporting evidence and results from the surveys, level of evidence and agreement.
Conclusion: We have developed the first evidence and expert opinion based recommendations to guide health professionals using IAT.

Acknowledgments: Eular Taskforce grant CL109

Disclosure of Interests: Jacqueline Uson Jaeger: None declared, Esperanza Naredo: None declared, Sebastian C Rodriguez-García Speakers bureau: Novartis Farmaceutica, S.A., Merck Sharp \& Dohme España, S.A., Sanof Aventis, UCB Pharma, Raul Castellanos-Moreira: None declared, Terence O'Neill: None declared, Hemant Pandit Grant/research support from: Glaxo Smith Kline (GSK) for work on Diclofenac Gel, Speakers bureau: Bristol Myers Squibb for teaching their employees about hip and knee replacement, Michae Doherty Grant/research support from: AstraZeneca funded the Nottingham Sons of Gout study, Consultant of: Advisory borads on gout for Grunenthal and Mallinckrodt, Mikael Boesen Consultant of: AbbVie, AstraZeneca, Eli Lilly, Esaote, Glenmark, Novartis, Pfizer, UCB, Paid instructor for: IAG, Image Analysis Group AbbVie, Eli Lilly, AstraZeneca, esaote, Glenmark, Novartis, Pfizer, UCB (scientific advisor)., Speakers bureau: Eli Lilly, Esaote, Novartis, Pfizer, UCB, Ingrid Möller: None declared, Valentina Vardanyan: None declared, Jenny de la TorreAboki: None declared, Lene Terslev: None declared, Francis Berenbaum Grant/ research support from: TRB Chemedica (through institution), MSD (through institution), Pfizer (through institution), Consultant of: Novartis, MSD, Pfizer, Lilly, UCB, Abbvie, Roche, Servier, Sanofi-Aventis, Flexion Therapeutics, Expanscience, GSK, Biogen, Nordic, Sandoz, Regeneron, Gilead, Bone Therapeutics, Regulaxis, Peptinov, 4P Pharma, Paid instructor for: Sandoz, Speakers bureau: Novartis, MSD, Pfizer, Lilly, UCB, Abbvie, Roche, Servier, Sanofi-Aventis, Flexion Therapeutics, Expanscience, GSK, Biogen, Nordic, Sandoz, Regeneron, Gilead Sandoz, Maria Antonietta D’Agostino Consultant of: AbbVie, BMS, Novartis, and Roche, Speakers bureau: AbbVie, BMS, Novartis, and Roche, Willm Uwe Kampen: None declared, Elena Nikiphorou: None declared, IRENE Pitsillidou: None declared, Loreto Carmona Grant/research support from: Novartis Farmaceutica, SA, Pfizer, S.L.U., Merck Sharp \& Dohme España, S.A., Roche Farma S.A, Sanofi Aventis, AbbVie Spain, S.L.U., and Laboratorios Gebro Pharma, SA (All trhough institution)

DOI: 10.1136/annrheumdis-2020-eular.833

\section{FRI0428 RESULTS FROM A CROSS-SECTIONAL, OBSERVATIONAL STUDY TO ASSESS INADEQUATE PAIN RELIEF IN PATIENTS WITH KNEE AND/OR HIP OSTEOARTHRITIS IN CHINA}

X. Zeng ${ }^{1}$, X. Leng ${ }^{1}$, K. Wei ${ }^{2}$, W. M. Tang ${ }^{2}$, C. H. Tang ${ }^{2}$, K. Tunceli ${ }^{3}$, J. Aggarwal ${ }^{4}$, D. Ramey ${ }^{3}$, F. Lozano ${ }^{5}$, I. Doshi ${ }^{3}$, C. Macahilig ${ }^{6}$, S. Odak ${ }^{6}$, K. Johnson ${ }^{3}$. ${ }^{1}$ Peking Union Medical College Hospital, Beijing, China; ${ }^{2}$ MSD Pharmaceutical, Shanghai, China; ${ }^{3}$ Merck \& Co., Inc. Center for Observational and Real World Evidence, Kenilworth, United States of America: ${ }^{4}$ Pharmerit International, LP., Boston, United States of America; ${ }^{5}$ Merck \& Co., Inc. Global Medical Affairs, Kenilworth, United States of America; ${ }^{6}$ Medical Data Analytics, Research Operations, Parsippany, United States of America

Background: Osteoarthritis (OA) of the knee and hip is a leading cause of disability worldwide, particularly due to the primary symptom of pain in the weight-bearing joints. There is limited data that characterizes patients who experience moderate to severe pain despite analgesic treatment in China.

Objectives: This study estimates the real-world prevalence of inadequate pain relief (IPR) among patients with knee and/or hip OA who have been prescribed analgesic therapy and characterizes this patient population. The study was conducted in China, the Philippines, Thailand, Russia, and Mexico. This abstract presents results from China.

Methods: This is a multinational, multi-site, cross-sectional, observational study. Physicians managing patients with OA were recruited and asked to enrol patients over 50 years of age with knee and/or hip OA who had been prescribed topical and/or oral pain medication for at least 30 days prior to study visit. Patients completed a one-time assessment of pain, function, and health-related quality of life (HRQOL) using patient reported outcome (PRO) instruments. Physicians abstracted data from patient charts. IPR was defined as an average pain score of $>4 / 10$ on Brief Pain Inventory Question \#5 (average pain). Statistical tests including chi-square for categorical variables and Mann-Whitney Wilcoxon test for continuous variables were conducted to assess differences in demographic and clinical characteristics as well as PROs between patients with and without IPR. A multivariate regression analysis was conducted to assess the relationship between IPR and PROs.

Results: 571 patients treated at 10 hospital centers in China were enrolled. $73 \%$ were female, the mean (SD) age was $62(8.32)$ years. The number of years with $\mathrm{OA}$ ranged from less than one year to over 37 years, suggesting a broad sample of patients. Most patients were impacted by knee OA only $(90 \%)$. Almost half $(43 \%)$ of the study population met the definition of IPR. Patients with IPR tended to be older, have greater prevalence of obesity, have more comorbidities and had longer disease duration. The majority (98\%) of patients were receiving nonsteroidal anti-inflammatory drugs (NSAIDS), followed by chondroprotective 